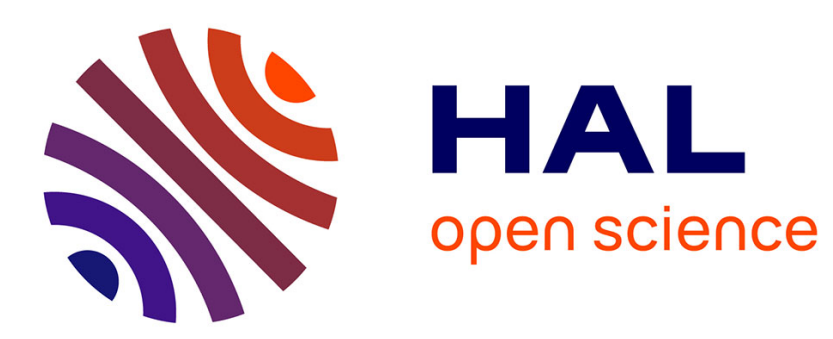

\title{
From differential induction of UDP-glucuronosyltransferases in rat liver to characterization of responsible ligand-activated transcription factors, and their multilevel crosstalk in humans
}

Karl Walter Bock

\section{To cite this version:}

Karl Walter Bock. From differential induction of UDP-glucuronosyltransferases in rat liver to characterization of responsible ligand-activated transcription factors, and their multilevel crosstalk in humans. Biochemical Pharmacology, 2011, 82 (1), pp.9. 10.1016/j.bcp.2011.03.011 . hal-00701263

\section{HAL Id: hal-00701263 \\ https://hal.science/hal-00701263}

Submitted on 25 May 2012

HAL is a multi-disciplinary open access archive for the deposit and dissemination of scientific research documents, whether they are published or not. The documents may come from teaching and research institutions in France or abroad, or from public or private research centers.
L'archive ouverte pluridisciplinaire HAL, est destinée au dépôt et à la diffusion de documents scientifiques de niveau recherche, publiés ou non, émanant des établissements d'enseignement et de recherche français ou étrangers, des laboratoires publics ou privés. 


\section{Accepted Manuscript}

Title: From differential induction of

UDP-glucuronosyltransferases in rat liver to characterization

of responsible ligand-activated transcription factors, and their

multilevel crosstalk in humans

Author: Karl Walter Bock

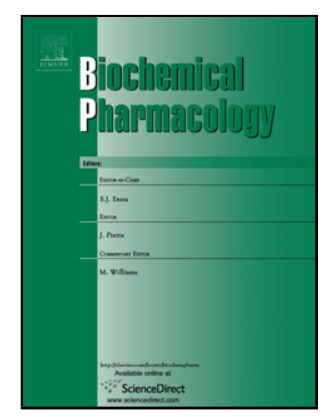

PII:

S0006-2952(11)00178-X

DOI: doi:10.1016/j.bcp.2011.03.011

Reference: BCP 10851

To appear in: $\quad B C P$

Received date: $\quad$ 15-2-2011

Revised date: $\quad 9-3-2011$

Accepted date: $\quad 9-3-2011$

Please cite this article as: Bock KW, From differential induction of UDPglucuronosyltransferases in rat liver to characterization of responsible ligandactivated transcription factors, and their multilevel crosstalk in humans, Biochemical Pharmacology (2010), doi:10.1016/j.bcp.2011.03.011

This is a PDF file of an unedited manuscript that has been accepted for publication. As a service to our customers we are providing this early version of the manuscript. The manuscript will undergo copyediting, typesetting, and review of the resulting proof before it is published in its final form. Please note that during the production process errors may be discovered which could affect the content, and all legal disclaimers that apply to the journal pertain. 
From differential induction of UDP-glucuronosyltransferases in rat liver to characterization of responsible ligand-activated transcription factors, and their multilevel crosstalk in humans

Karl Walter Bock*

Department of Toxicology, Institute of Experimental and Clinical Pharmacology and Toxicology. University of Tübingen, Wilhelmstrasse 56, D-72074 Tübingen, Germany

Abbreviations: AhR, Ah receptor; BaP, benzo[a]pyrene; CAR, constitutive androstane receptor; CYP, cytochrome P450; GR, glucocorticoid receptor; GST, glutathione Stransferase; gtPBREM (glucuronyltransferase Phenobarbital-Responsive Enhancer Module); HETE, hydroxyeicosatetraenoic acid; LATFs, ligand-activated transcription factors; LTB4, leucotriene B4; Nrf2, nuclear erythroid-related factor 2; PB, phenobarbital; PXR, pregnane $X$ receptor; PPARa, peroxisome proliferator-activated receptor $\alpha$; ROS, reactive oxygen species; UGT, UDP-glucuronosyltransferase; XME, xenobiotic-metabolizing enzyme

\footnotetext{
* Tel.: +49 7071 2972274; Fax: +49 707129227

E-mail address: bock@uni-tuebingen.de
} 


\section{ABSTRACT}

UDP-glucuronosyltransferases (UGTs) catalyze a major Phase II reaction in the endo- and xenobiotic-metabolizing enzyme (XME) system consisting of Phases I - III proteins and ligand-activated transcription factors. Differential induction of liver microsomal CYP activities following treatment of rats with aryl hydrocarbons or phenobarbital, discovered over 50 years ago, initiated studies to characterize multiple CYPs and the transcription factors Ah receptor (AhR) and CAR, respectively. Similar studies of UGT activities initiated studies of multiple UGTs. However, inducible human UGTs differed from those in rats. In addition, induction of UGTs is complicated, for example, by coordinate regulation of some XMEs by AhR and the antioxidant Nrf2 transcription factor. Functions of UGTs in the XME system are discussed using the following examples: (i) Tight coupling between Phase I and II enzymes in benzo[a]pyrene detoxification. In particular, AhR- and Nrf2-controlled quinone reductases and UGTs may prevent quinone-quinol redox cycling with generation of oxidative stress. (ii) CAR-mediated induction of UGT1A1 may be involved in perinatal detoxification of bilirubin neurotoxicity. (iii) PPARa-mediated glucuronidation of eicosanoids may contribute to their detoxification and homeostasis. Identification of the role of UGTs is challenged by intense crosstalk of transcription factors at the genetic level, the level of protein-protein interaction and control by signaling networks. Nevertheless, as drug targets ligand-activated transcription factors provide promising therapeutic possibilities.

Key words: Hepatic UGTs; Induction; Ligand-activated transcription factors; Ah receptor; CAR/PXR; Crosstalk 


\section{Introduction}

Differential induction of microsomal CYP activities by aryl hydrocarbons and phenobarbital was discovered over 50 years ago [1-4], and facilitated characterization of the CYP supergene family $[5,6]$. This discovery also stimulated identification of the responsible ligand-activated transcription factors (LATFs): AhR [7,8], CAR and PXR [9-11]. In addition, treatment of rats with fibrates led to their characterization as peroxisome proliferators [12], CYP4 family inducers [5], and identification of PPARa as the responsible LATF [13]. It was soon recognized that these inducers also differentially activated other xenobiotic-metabolizing enzymes (XMEs), for example, UGT supergene family members [14] which similar to CYPs are differentially induced in rat liver by aryl hydrocarbons, phenobarbital and fibrates [1517]. Recognition of common LATF-binding response elements in the regulatory region of target genes suggests that Phase I and II XMEs, drug transporters (Phase III) as well as LATFs represent an evolutionary conserved detoxification system for lipid-soluble endo- and xenobiotics $[5,11,18,19]$. They are often functionalized in Phase I, conjugated in Phase II, and the water-soluble conjugates are exported from cells by transporters in Phase III. In addition, this system may also have evolved to regulate homeostasis of endobiotics [20] (Fig. 1). Phase I and II XMEs are also termed drug-metabolizing enzymes because of their importance for drug development and therapy.

The present commentary is focused on UGTs which exhibit a central role in the XME system, acting together with CYPs, and conjugate transporters. Control of CYP induction by LATFs has been covered in a number of elegant reviews $[5,11,21,22]$. Despite common LATFs for different XMEs, special regulatory mechanisms have been recognized for Phase II enzymes such as UGTs and glutathione S-transferases (GSTs). For example, both AhR and the antioxidant Nrf2/Keap1 pathway are required for induction of UGTs. Recently, species differences in regulation of UGTs, and crosstalk between LATFs have become a major challenge. Therefore, the present commentary emphasizes regulation of human hepatic UGTs by LATFs and their multilevel crosstalk. 
2. Overview of ligand-activated transcription factors (LATFs) responsible for induction of CYPs and UGTs

Ligand-activated transcription factors (LATFs) regulate hepatic XMEs in cooperation with liver-enriched transcription factors including HNF1, HNF4 and C/EBP [23-25]. Interestingly, when hepatic cell lines were supplemented with C/EBP-, HNF4a- and CAR-expressing vectors, expression of CYP2B6 and UGT1A1 was synergistically enhanced [26]. These findings underline the importance of cooperation between liver-enriched transcription factors and LATFs. LATFs responsible for induction of XMEs represent an interesting subgroup of transcription factors which acquired the ability to be modulated by small molecules in a manner similar to allosteric regulation of enzymes. Notably, the discussed LATFs are again under the control of higher order transcription factors. For example, the Wnt/B-catenin/TCF pathway may control both AhR and CAR. AhR and CAR expression are decreased in livers of ctnnb1deficient male and female mice whereas PXR, PPAR $\alpha$ and Nrf2 remained unaffected. Expectedly, expression of UGT1A6a and $1 \mathrm{a} 6 \mathrm{~b}$ were found to be decreased in these animals. The finding that $A h R$ is a target of $B$-catenin signaling has also been reported by others ([27] for references).

\subsection{Ah receptor (AhR)}

The AhR represents a multifunctional switch involved, for example, in metabolic adaptation, vascular development and dioxin-mediated toxicities [7]. In addition to xenobiotic aryl hydrocarbons and dioxins, a variety of endogenous ligands are presently discussed together with non-ligand activators [8]. Ligand-binding leads to nuclear translocation of the cytosolic AhR where it associates with its partner protein Arnt and binds to XREs (xenobiotic response elements) containing the core DNA sequence TnGCGTG. The first XRE was characterized in the promoter region of CYP1A1 [28]. In the case of UGTs, XREs were first identified in the regulatory region of rat liver UGT1A6 [29], human UGT1A6 [30,31] and human UGT1A1 [32]. In fact, all human UGT1 family members appear to be regulated by the AhR [33] in cooperation with subsequently discussed Nrf2.

\subsection{Nrf2-Keap1 signaling}

Treatment of rats with antioxidants/electrophiles leads to induction of Phase II enzymes and a battery of oxidative stress response genes [34-36]. In contrast, 
CYP1A1 was found to be downregulated by oxidative stress [37]. Search for the responsible transcription factor led to identification of Nrf2 [38-40]. Nrf2 is sequestered in the cytoplasm in complex with Keap1 (kelch-like ECH-associated protein 1). Nrf2 and Keap1 dissociate when Keap1 reacts with ROS (reactive oxygen species), other electrophiles and antioxidants. Thereafter, Nrf2 migrates to the nucleus where it associates with small Maf or related proteins and binds to AREs (antioxidant responsive elements) in target genes $[40,41]$. The first ARE was identified in the regulatory region of GSTA2 [41]. Nrf2-regulated genes such as UGT1A6 were identified using Nrf2-deficient and proficient mice induced by the selective Nrf2/Keap1 activator sulforaphane. Results of these studies suggested that glucuronidation and glutathione conjugation are 'more dependent on Nrf2-regulated genes than thought previously' [40]. Not only UGT1 and UGT2 genes but also UDPglucose dehydrogenase (the enzyme generating the cofactor UDP-glucuronic acid) were found to be upregulated. Recently, it has been established that coordinate regulation of AhR and Nrf2 is required for induction of murine UGTs [42] and probably rat and human UGTs as well $[31,43]$. Roles of coordinate AhR and Nrf2 induction in detoxification and mechanisms of multilevel crosstalk are discussed in sections 4 and 5, respectively. Notably, Nrf2 is not a LATF: The protein interacting with electrophiles and ROS is Keap1. Release from binding to Keap1 leads to activation of Nrf2. However, due to necessary interaction between AhR and Nrf2 for induction of UGTs, Nrf2 is discussed here together with LATFs.

\section{3. $C A R$ and $P X R$}

CAR (constitutive androstane receptor, NR1/3) and PXR (pregnane $X$ receptor, NR1I2) are closely related, evolutionary-conserved xenobiotic sensors of the nuclear receptor superfamily $[10,11,21]$. They are discussed together since they share common activators and target genes. On the other hand, distinct activators and activation mechanisms are also known. For example, human PXR is selectively and directly activated by the antibiotic rifampicin; CAR is indirectly activated by phenobarbital-type inducers such as the antiepileptics phenobarbital, phenytoin and carbamazepin. The latter inducers do not bind to the CAR protein but trigger its nuclear translocation by a mechanism involving dephosphorylation of its threonine 38 [44]. However, how the cell recognizes phenobarbital-type inducers is still a mystery. Induction of UGTs by phenobarbital is known from early clinical studies. In fact, 
Crigler-Najjar syndromes I and II habe been distinguished on the basis of phenobarbital induction of UGT1A1 [45]. CAR/RXR-binding domains were first identified in studies of UGT1A1 regulation [46,47], the only UGT responsible for bilirubin clearance in humans. Interestingly, the CAR-binding domain resides in a 290 base pair cluster, termed gtPBREM (glucuronosyltransferase PhenobarbitalResponsive Enhancer Module), discussed in section 4.2. With regard to PXR it is known that this LATF transcriptionally activates a number of UGTs: UGT1A1 (in the gtPBREM cluster) [47] and also UGT1A3, 1A4 and 1A6 [24].

\subsection{PPARa}

Several evolutionary conserved PPAR isoforms have been identified. Here, the focus is on fibrate-activated hepatic PPARa which controls mitochondrial and peroxisomal B-oxidation of fatty acids $[12,13]$. Fatty acids and eicosanoids have been identified as potent endogenous ligands of PPAR $[48,49]$. For example, 8(S)-HETE has been demonstrated to be a high-affinity ligand with $100 \mathrm{nM}$ half-maximal activity [48]. PPARa has been shown to be involved in all pleiotropic effects of peroxisome proliferators [50]. CYP4 family members were the first fibrate-induced XME target genes shown to be involved in omega-hydroxylation of fatty acids [5]. PPARa is involved in regulation of all phases of the XME system including regulation of many UGTs (UGT1A1, 1A3, 1A4 [51], 1A9 [52], 2B4 [53]). PPARa-induced hepatic UGTs are possibly involved in detoxification of eicosanoids, as discussed in section 4.4.

3. Species differences of rat and human hepatic UGT induction by ligand-activated transcription factors (LATFs)

As discussed in the previous section, studies with LATF-deficient mice and with transgenic mice expressing human UGTs suggest that expression of UGTs is regulated by LATFs together with liver-enriched transcription factors. Notably, LATFs such as AhR are required to maintain both basal and ligand-induced UGT1A6 expression in mouse liver [54]. Species differences are expected since each species conceivably selects the regulatory conditions suitable for its ecological niche. As indicated in Table 1, differential induction of orthologous hepatic UGT1 members by AhR and CAR/PXR is obvious in rats but not in humans.. In rat liver UGT1A6 is markedly induced by aryl hydrocarbons while UGT1A1 is not induced. In contrast, human UGT1A1 is induced by aryl hydrocarbons [33] while induction of UGT1A6 is 
low. Summing up all available information, induction of human UGTs is indicated by

$(+)$ in Table 1, despite < 2-fold induction in some studies [55].

UGT2 members of different species cannot be compared since no orthologous UGT2 genes can be identified. Interestingly, expression of human hepatic UGT2 members (UGT2B4, 2B7, 2B10, 2B15 and 2B17) is in general higher than that of family 1 members [56,57]. UGT2 members are known to be involved in catabolism of steroids and bile acids. For example, UGT2B15 and 2B17 are strongly regulated by androgens [58]. Abundantly expressed UGT2B4 is regulated by bile acid-activated PPARa [52]. However, the contribution of UGTs in detoxification of steroids and bile acids is complex and beyond the scope of this commentary. The role of UGT2B4 in catabolism of eicosanoids is discussed in section 4.4.

Human intestinal and hepatic UGTs are induced via AhR and Nrf2 by dietary phytochemicals [59], including unknown constituents of commonly consumed coffee [60]. Notably, the Nrf2 pathway induces both UGT1 and UGT2 family members. Nrf2binding AREs have been identified in the promoter of UGT2B7 [61]. As discussed in section 4.4, UGT2B7 is involved in detoxification of inflammatory eicosanoids such as HETEs and LTB4. Hence, Nrf2-mediated induction of UGTs may contribute to the hepatic antioxidant defense capacity which is possibly involved in prevention or amelioration of hepatitis $[62,63]$.

Studies of human liver banks revealed large interindividual variation of UGT activities [56]. However, underlying factors (LATFs, liver-enriched transcription factors as well as genetic diversity [64]) are difficult to distinguish. In addition, recent evidence supports the concept that UGT proteins interact as dimers/oligomers which may have implications for structure, function and substrate specificity of UGTs [65]. Moreover, UGT activity may be controlled by regulated phosphorylation [66]. Despite these complexities, control of gene expression is important. It is proposed that it is mainly the concerted action of UGTs together with other members of the XME system which leads to effective detoxification, as indicated in the subsequent section.

4. Roles of UGTs in detoxification and homeostasis of xeno- and endobiotics

\subsection{Roles of Phase I and II induction in detoxification of polycyclic aromatic hydrocarbons}


Roles of CYP1A1 and CYP1B1 induction in bioactivation of carcinogenic polycyclic aromatic hydrocarbons such as benzo[a]pyrene (BaP) has been well studied and controversially discussed. In particular, mouse lines deficient in one or another of the CYP1 genes have shown paradoxical effects [67]. When CYP1A1-deficient mice received $\mathrm{BaP}$ orally $(125 \mathrm{mg} / \mathrm{kg} /$ day) all animals died within 30 days whereas all CYP1-induced wild-type mice survived, suggesting efficient BaP detoxification (rather than bioactivation) by the intestinal epithelium. In support of this interpretation, serum $\mathrm{BaP}$ was much higher in CYP1A1-deficient mice. Efficient detoxification has been proposed to be achieved by the degree of coupling between Phase I - III metabolism. $\mathrm{BaP}$ metabolism is complex leading, for example, (i) to $\mathrm{BaP}-7,8-$ dihydrodiol and $\mathrm{BaP}$ diol epoxides (the latter as ultimate genotoxic carcinogens) and (ii) to multiple $\mathrm{BaP}$ quinones as major cytotoxic tumor promoters/progressors $([59,68]$ for references). $\mathrm{BaP}$ quinones such as BaP-3,6-quinone have been identified as potent activators of $\mathrm{AhR}$ and Nrf2, the latter due to oxidative stress generated by quinone-semiquinonequinol redox cycles [69]. Reductases such as NADPH-cytochrome P450 reductase reduce quinones by risky 1-electron pathways. However, there are also multiple Nrf2inducible quinone reductases including NQO1 $(\mathrm{NAD}(\mathrm{P}) \mathrm{H}$ quinone reductase 1) which reduce quinones by 2-electron pathways whereby the toxic semiquinone step is bypassed. Efficient glucuronidation of the resulting quinols by coinduced UGT1A9 [70] (termed UGT1.7 in the early publication) may prevent oxidative stress. In support of oxidative stress as major trigger of the Nrf2 response, studies with NQO1-deficient Caco-2 cells led to induction of UGT1A6 by tert-butylhydroquinone whereas no induction was achieved in NQO1-proficient HT-29 cells [71]. In addition to oxidation to the diol epoxide, BaP-7,8-dihydrodiol may be converted to BaP-7,8-quinol by AKRs (aldoketo reductases) such as AKR1C1 which is AhR- and Nrf2 inducible [72]. The quinol is autoxidized to BaP-7,8-quinone and undergoes redox cycling with generation of oxidative stress [72]. The quinol may also be detoxified by UGTs and SULTs (sulfotransferases) but the responsible isoforms have not been identified. In conclusion, coordinate induction of AhR and Nrf2 gene batteries may be an example for detoxification of BaP by tight coupling between Phase I and II enzymes. Of course, the proposed roles of human AhR- and Nrf2-inducible UGTs in detoxification of carcinogenic polycyclic aromatic hydrocarbons need to be verified by epidemiologic studies using UGT polymorphisms, similar to the study of the role of UGT1A7 in smoking-related laryngeal cancer [73]. 


\subsection{Perinatal UGT1A1 induction}

Perinatal induction of UGTs by phenobarbital has been investigated for decades.

Early studies suggested that 'late fetal and neonatal clusters' of inducible rat hepatic UGT activities [74] were identical to aryl hydrocarbon- and phenobarbital-inducible UGT activities, respectively $[15,16]$. Induction of UGTs from low fetal UGT activities to perinatal and adult values has been reviewed [56]. Low bilirubin UGT activity (in addition to hemolytic conditions) was found to be the major factor responsible for severe neonatal jaundice which is particularly frequent in preterm infants. Hyperbilirubinemia is neurotoxic in the neonate leading to brain damage, known as 'kernicterus' [75]. It is tempting to speculate that evolution of the gtPBREM cluster of binding sites for a number of LATFs in the promoter of UGT1A1 $[46,47]$ may be related to the need for perinatal UGT1A1 induction in primates. This cluster contains binding sites for CAR and PXR [47], AhR [33], Nrf2 [76], PPARa [51] and for the glucocorticoid receptor [47]. It is obvious that perinatal induction represents a stressful condition. Glucocorticoids and other stimuli may activate their response elements in the gtPBREM of UGT1A1. Glucocorticoids have been demonstrated to induce CAR and PXR expression [22]. Hence, activation of different LATFs in the gtPBREM cluster depends upon the presence of activating ligands. Interestingly, the gtPBREM is perfectly conserved in the baboon [77]. It is localized at a similar distance to the transcription start site, and the sequence of cis-acting response elements for LATF-binding is highly conserved.

\subsection{Possible autoregulatory control of UGT1A1 by bilirubin}

Studies using CAR-defective mice demonstrated that all proteins involved in bilirubin clearance by hepatocytes are under the control of CAR including OATP1B1 and 1B3 (uptake transporters for bilirubin and bilirubin monoglucuronide into hepatocytes), GSTA1/2 (involved in intracellular binding of bilirubin), bilirubin conjugating UGT1A1 and Mrp2 (responsible for biliary secretion of bilirubin conjugates [78]. Low CAR expression in the fetus may contribute to neonatal jaundice [78]. Bilirubin is the toxic end product of heme catabolism. A significant amount of bilirubin is produced every day (250-400 mg in adult humans) which is cleared in the liver by the above CARregulated XME system. Interestingly, bilirubin is an activator of CAR [78] and of AhR ([8], for references). In support of the role of these LATFs in bilirubin catabolism, UGT1A1 has been demonstrated to be induced by aryl hydrocarbons and 
phenobarbital-type inducers in human primary hepatocyte cultures [79]. Bilirubin clearance is also enhanced by activators of PXR [80]. Hence, bilirubin-activated LATFs may provide an autoregulatory feedback loop which is not only operative in the stressful perinatal period but also in the adult.

In addition, the bilirubin-mediated autoregulatory feedback loop appears to be finetuned since bilirubin is not only neurotoxic in the neonate but also a powerful antioxidant $[81,82]$. The latter property may have facilitated the occurrence of a frequent polymorphism of UGT1A1, termed UGT1A $1{ }^{*} 28$, responsible for Gilbert's syndrome. Homozygous expression of this allelic variant results in reduced expression of UGT1A1, moderately increased serum bilirubin, and may be responsible for reduced coronary disease in carriers of Gilbert's syndrome [83]. Interestingly, in the gtPBREM cluster a polymorphism (T3279G) was found in linkage disequilibrium with the UGT1A $1{ }^{*} 28$ polymorphism which synergistically lowers UGT1A1 expression $[84,85]$.

\subsection{Control of eicosanoid catabolism by UGTs}

Vasoactive and inflammatory eicosanoids activate LATFs and are detoxified by UGTs (Fig. 2). CYP4 family members are known to be involved in omega-hydroxylation of fatty acids, for example, human hepatic CYP4F3B is involved in omega oxidation of arachidonic acid to vasoactive 20-HETE (20-hydroxyeicosatetraenoic acid) [86]. 20HETE is glucuronidated by several PPARa-induced UGTs, mainly by UGT2B7 [87]. It has been shown to be excreted in urine as 20-HETE glucuronide, particularly in liver cirrhosis [62,63]. In addition, arachidonic acid is oxidized by 5-LOX (5-lipoxygenase) to labile LTA4 which is converted either to vasoconstrictory LTC4 (leucotriene C4), or inflammatory LTB4, a known substrate of UGT2B7 $[87,88]$. Multiple HETEs have been characterized as PPARa agonists $[11,48]$. They are also substrates of UGT1A1,1A3,1A4,1A6,1A9 [51], and UGT2B4, 2B7 and 2B10 [87]. Interestingly, a stepwise increase in LOX metabolites such as 12- and 15-HETE characterizes the progression from normal liver to nonalcoholic fatty liver disease and steatohepatitis [63]. It is tempting to speculate that these UGTs may be involved in the prevention or attenuation of eicosanoid-mediated inflammatory responses in the initial stages of hepatitis. However, experimental approaches are needed to substantiate the role of UGTs in eicosanoid detoxification in vivo. 


\section{Multilevel crosstalk of LATFs controlling UGTs}

Currently, crosstalk between LATFs and tissue-specific transcription factors in regulation of UGTs [24] and among LATFs represents a major challenge which is just beginning to be understood. It occurs at multiple levels: at the genetic level or by recruitment of coregulators which again are embedded in signaling networks and epigenetic signatures. A few examples have been selected (Table 2).

\subsection{AhR-Nrf2}

Accumulating evidence in mice suggests that coordinate activation of AhR and Nrf2 may be required for induction of NQO1 as well as most GSTs and UGTs [42]. In support of these findings, experiments using AhR-deficient and -proficient rat hepatoma $5 \mathrm{~L}$ cells suggest that $\mathrm{AhR}$ is necessary for induction by tertbutylhydroquinone, a prototypical activator of Nrf2-Keap1 signaling [31]. In humans, UGT1 members also appear to be regulated by both AhR and Nrf2 $[43,89]$.

At the genetic level, Nrf2 has been found to be a target gene of AhR, based on functional XREs identified in the promoter of Nrf2 [90], On the other hand, AhR appears to be a target gene of Nrf2 [91]. However, coordinate induction of UGTs by AhR and Nrf2 may also be possible by direct or indirect (via coregulators) interaction between the two transcription factors, as discussed for the control of NQO1 [92]. Many questions remain: For example, does this AhR-Nrf2 crosstalk apply to all Nrf2regulated genes? Do we have to distinguish regulation of Phase II XMEs from other antioxidant enzymes such as heme oxygenase 1, thioredoxin reductase etc? LATFs and functionally connected Nrf2 are multifunctional switches. Probably there is no clear distinction between their roles in regulating XMEs and other functions. Better knowledge about LATF-binding response elements of target genes may help to solve some of the problems.

\subsection{AhR-nuclear receptor family members}

CAR expression appears to be induced by TCDD via AhR in human liver [93], and some evidence for crosstalk between PXR and AhR has been obtained in human 
liver: rifampicin induces $\mathrm{CYP} 1 \mathrm{~A} 1$ and $1 \mathrm{~A} 2$ via $\mathrm{AhR}$ in human primary hepatocyte cultures [94], although this finding remains complex and controversial [22]. PXR expression appears to be controlled by PPARa, based on PXR expression and PPREs in the promoter region of PXR [95].

\subsection{Recruitment of coregulators}

When LATFs bind to DNA, coregulators are recruited and corepressors are released. Coacticators are known to be involved in epigenetic chromatin remodeling, for example via histone acetyltransferases/deacetylases. In addition, mediator complexes are formed in multiple steps which are responsible for interaction of LATF complexes with the RNA polymerase II complex of the basal transcription machinery. A few examples of LATF coactivators controlling UGTs have been described. For example, CAR and GR synergistically crosstalk in UGT1A1 expression by recruitment of the coregulator GRIP1 (glucocorticoid receptor-interacting protein 1) [96]. Crosstalk between GR and CAR has been discussed in section 4.2. It may be particularly important during perinatal adaptation to avoid bilirubin-mediated brain injury. Furthermore, CAR and PPARa transcription is only possible by interaction with the coregulator/mediator PBP/TRAP220: Conditional deletion of PBP/TRAP220 in hepatocytes abrogates all PPAR $\alpha$ and CAR functions, i. e., phenotypes of $\mathrm{PBP} / T R A P$-deficient mice are similar to those in mice lacking the respective receptor [97].

5.4. Control of ligand-activated transcription factors (LATFs) by protein kinases/phosphatases

Expectedly, LATFs are embedded in complex protein kinase/phosphatase signaling networks. The role of non-ligand activation of AhR has been critically discussed in [8]. As discussed before, phenobarbital-mediated nuclear translocation of CAR depends upon dephosphorylation of threonine 38 [44]. Studies using the II-6-type cytokine oncostatin M provide an interesting example for LATF control by protein kinases. Oncostatin $\mathrm{M}$ binds to a plasma membrane receptor complex which, in contrast to other cytokines such as EGF, IL-1ß and IL-6, positively enhances the CAR-UGT1A1 pathway via MAP kinase [98]. The cytokine is an important developmental factor of hepatocyte maturation and may contribute to perinatal induction of UGT1A1. 


\section{Conclusions}

UDP-glucuronosyltransferases (UGTs) catalyze a major Phase II reaction in the endo- and xenobiotic-metabolizing enzyme (XME) system consisting of Phases I - III proteins and ligand-activated transcription factors (LATFs). LATFs represent an interesting subgroup of transcription factors which acquired the ability to be modulated by small molecules in a manner similar to allosteric regulation of enzymes. Differential induction of liver microsomal CYP activities following treatment of rats with aryl hydrocarbons or phenobarbital, discovered over 50 years ago, initiated studies on multiple CYPs and the responsible transcription factors, Ah receptor (AhR) and CAR, respectively. Similar studies of UGT activities initiated studies of multiple UGTs. However, inducible human UGTs differed from those in rats. For example, rat hepatic UGT1A6 is markedly induced by aryl hydrocarbons while rat UGT1A1 is not induced. In contrast, human UGT1A1 is induced by aryl hydrocarbons [79] while induction of human UGT1A6 is low . In addition, induction of UGTs is complicated by coordinate regulation of some XMEs by AhR and the antioxidant transcription factor Nrf2. Notably, Nrf2 is not a LATF. The protein interacting with endo- and xenobiotic electrophiles and ROS is Keap1, the cytosolic partner of Nrf2. Nevertheless, due to close coregulation of AhR and Nrf2 in the induction of UGTs (and of GSTs, NQO1 and AKR1C1) it may be justified to discuss Nrf2 together with LATFs.

Functions of UGTs in the XME system have been discussed using detoxification of aryl hydrocarbons such as benzo[a]pyrene, bilirubin and eicosanoids as examples. (i) Tight coupling between Phases I - III enzymes in benzo[a]pyrene (BaP) detoxification may explain in part paradoxical observations of AhR-mediated induction in cell cultures and in vivo. Whereas AhR-induced CYP1A1 is known to be responsible for $\mathrm{BaP}$ bioactivation in cell culture, CYP1A1-deficient mice were not protected against oral BaP exposure. In contrast, CYP1A1-inducible mice survived whereas CYP1A1-deficient mice died due to lack of intestinal first-pass BaP detoxification [67]. Tight coupling of Phases I - III may be responsible for protection of the intestinal epithelium. In particular, AhR- and Nrf2-controlled quinone reductases and UGTs may prevent quinone-quinol redox cycling and subsequent generation of oxidative stress. Quinone reductases such as NQO1 reduce quinones by 2-electron reduction thereby bypassing the toxic semiquinone step; UGTs such as UGT1A9 
have been shown to efficiently conjugate the resulting $\mathrm{BaP}$ quinols [70] which are rapidly exported by transporters.

(ii) CAR-mediated induction of UGT1A1, the only human UGT responsible for bilirubin conjugation, may be involved in perinatal detoxification of bilirubin neurotoxicity. The perinatal induction of fetal UGT1A1 is an impressive adaptive process. It is proposed that the gtPBREM cluster (containing binding sites for AhR, Nrf2, CAR, PXR, PPARa and the glucocorticoid receptor) in the regulatory region of this enzyme is involved in this stress-mediated adaptation. In addition, bilirubin has been shown to activate AhR and CAR, in support of an autoregulatory loop.

(iii) PPARa-mediated glucuronidation of eicosanoids may contribute to their detoxification and homeostasis. Vasoactive and inflammatory eicosanoids such as 20-HETE and LTB4 have been shown to be detoxified by UGTs, and these eicosanoids are agonists of PPARa.

Identification of the role of UGTs is challenged by intense crosstalk of transcription factors at the genetic level, the level of protein-protein interaction and control by signaling networks, as examplified by regulation of UGT1A1. Numerous epidemiologic studies have shown an association between reduced cancer risk and increased intake of phytochemicals present in vegetables and fruits. Consumption of phytochemicals including the common beverage coffee has been shown to induce UGTs. Hence, ligand-activated transcription factors as drug targets may provide promising therapeutic possibilities.

Achnowledgements

The help of Dr. Christoph Köhle in preparing the figures is greatly appreciated. I apologize for often citing reviews istead of original papers to reduce the number of references. 


\section{References}

[1] Conney AH, Miller EC, Miller JA. The metabolism of methylated aminoazo dyes. V. Evidence for induction of enzyme synthesis in the rat by 3methylcholanthrene. Cancer Res 1956;16:450-9.

[2] Conney AH. Pharmacological implications of microsomal enzyme induction. Pharmacol Rev 1967;19:317-66.

[3] Remmer H. Die Beschleunigung des Evipanabbaues unter der Wirkung von Barbituraten. Naturwissenschaften 1958;8:189.

[4] Remmer H, Merker HJ. Drug-induced changes in the liver endoplasmic reticulum: association with drug-metabolizing enzymes. Science 1963;142:1657-8.

[5] Nebert DW, Gonzalez F. P450 genes: structure, evolution, and regulation. Ann Rev Biochem 1987;56:945-93.

[6] Nelson DR, Koymans L, Kamataki T, Stegeman JJ, Feyereisen R, Waxman DJ, et al. P450 superfamily: update on new sequences, gene mapping, accession numbers and nomenclature. Pharmacogenet 1996;6:1-42.

[7] Gu YZ, Hogenesch JB, Bradfield CA. The PAS superfamily: sensors of environmental and developmental signals. Ann Rev Pharmacol Toxicol 2000;40:51961.

[8] Nguyen LP, Bradfield CA. The search for endogenous activators of the aryl hydrocarbon receptor. Chem Res Toxicol 2008;21:102-16.

[9] Sueyoshi T, Negishi M. Phenobarbital response elements of cytochrome P450 genes and nuclear receptors. Ann Rev Pharmacol Toxicol 2001;41:123-43.

[10] Timsit YE, Negishi M. CAR and PXR: The xenobiotic sensing receptors. Steroids 2007;72:231-46.

[11] Chawla A, Repa JJ, Evans RM, Mangelsdorf DJ. Nuclear receptors and lipid physiology: opening the X-files. Science 2001;294:1866-70.

[12] Hess R, Stäubli W, Riess W. Nature of the hepatomegalic effect produced by ethylchlorophenoxyisobutyrate in the rat. Nature 1965;208:856-8. 
[13] Issemann I, Green S. Activation of a member of the steroid hormone receptor superfamily by peroxisome proliferators. Nature 1990;347:645-50.

[14] Mackenzie PI, Bock KW, Burchell B, Guillemette C, Ikushiro SI. lyanagi T, et al. Nomenclature update for the mammalian UDP glycosyltransferase (UGT) gene superfamily. Pharmacogenet Genomics 2005;15:677-85.

[15] Bock KW, Fröhling W, Remmer H, Rexer B. Effects of phenobarbital and 3methylcholanthrene on substrate specificity of rat liver microsomal UDPglucuronyltransferase. Biochim Biophys Acta 1973;327:46-56.

[16] Lilienblum W, Walli AK, Bock KW. Differential induction of rat liver microsomal UDP-glucuronosyltransferase activities by various inducing agents. Biochem Pharmacol 1982;31:907-13.

[17] Shelby MK, Klaassen. Induction of rat UDP-glucuronosyltransferases in liver and duodenum by microsomal enzyme inducers that activate various transcriptional pathways. Drug. Metab Disp 2006;34:1772-8.

[18] Goldstone JV, Hamdoun A, Cole BJ, Howard-Ashby M, Nebert DW, Scally M, et al. The chemical defensome: environmental sensing and response genes in the Strongylocentrotus purpuratus genome. Dev Biol 2006;300:366-84.

[19] Köhle C, Bock KW. Coordinate regulation of drug-metabolizing enzymes, and conjugate transporters by the Ah receptor, pregnane $X$ receptor and constitutive androstane receptor. Biochem Pharmacol 2009;77:689-99.

[20] Nebert DW. Proposed role of drug-metabolizing enzymes: regulation of steady state levels of the ligands that effect growth, homeostasis, differentiation, and neuroendocrine functions. Mol Endocrinol 1991;5:1203-14.

[21] Handschin C, Meyer UA. Induction of drug metabolism: the role of nuclear receptors. Pharmacol Rev 2003;55:649-73.

[22] Pascussi JM, Gerbal-Chaloin S, Duret C, Daujat-Chavanieu M, Vilarem MJ, Maurel P. The tangle of nuclear receptors that controls xenobiotic metabolism and transport: crosstalk and consequences. Ann Rev Pharmacol Toxocol 2008;48:1-32. 
[23] Hansen AJ, Lee YH, Sterneck E, Gonzalez FJ, Mackenzie PI. C/EBPa is a regulator of the UDP glucuronosyltransferase UGT2B1 gene. Mol Pharmacol 1998;53:1027-33.

[24] Mackenzie PI, Hu DG, Gardner-Stephen DA. The regulation of UDPglucuronosyltransferase genes by tissue-specific and ligand-activated transcription factors. Drug Metab Rev 2010;42:95-105.

[25] Lu H, Gonzalez FJ, Klaassen C. Alterations in hepatic mRNA expression of Phase-Il enzymes and xenobiotic transporters after targeted disruption of hepatocyte nuclear factor 4 alpha. Toxicol Sci 2010;118:380-90.

[26] Benet M, Lahoz A, Guzman C, Castell JV, Jover R. CCAAT/enhancer-binding protein $\alpha(\mathrm{C} / \mathrm{EBP} \alpha)$ and hepatocyte nuclear factor $4 \alpha$ (HNF4 4 ) synergistically cooperate with constitutive androstane receptor to transactivate the human cytochrome P450 2B6 (CYP2B6) gene. J Biol Chem 2010;285:28457-71.

[27] Braeuning A, Sanna R, Huelsken J, Schwarz M. Inducibility of drugmetabolizing enzymes by xenobiotics in mice with liver-specific knockout of Ctnnb1. Drug Metab Disp 2009;37:1138-45.

[28] Denison MS, Fisher JM, Whitlock JP. The DNA recognition site for the dioxinAh receptor complex. J Biol Chem 1988;263:17221-4.

[29] Emi Y, Ikushiro S, lyanagi T. Xenobiotic responsive element-mediated transcriptional activation in the UDP-glucuronosyltransferase family 1 complex. J Biol Chem 1996;271:3952-8.

[30] Münzel PA, Lehmköster T, Brück M, Ritter JK, Bock KW. Aryl hydrocarboninducible or constitutive expression of human UDP glucuronosyltransferase UGT1A6. Arch Biochem Biophys 1998;350:72-8.

[31] Münzel PA, Schmohl S, Buckler F, Jaehrling J, Raschko FT, Köhle C, et al. Contribution of the Ah receptor to the phenolic antioxidant-mediated expression of human and rat UDP-glucuronosyltransferase UGT1A6 in Caco-2 and rat hepatoma 5L cells. Biochem Pharmacol 2003;66:841-7. 
[32] Yueh MF, Huang YH, Hiller A, Chen S, Nguyen N, Tukey RH. Involvement of the xenobiotic response element (XRE) in Ah receptor-mediated induction of human UDP-glucuronosyltransferase 1A1. J Biol Chem 2003;278:15001-6.

[33] Chen S, Beaton D, Nguyen N, Seneko-Effenberger K, Brace Sinnokrak E, Argikar U, et al. Tissue-specific, inducible, and hormonal control of the human UDPglucuronosyltransferase-1 (UGT1) locus. J Biol Chem 2005;280:37547-57.

[34] Wattenberg LW. Effects of dietary constituents on the metabolism of chemical carcinogens. Cancer Res 1975;35:3326-31.

[35] Prochaska HJ, Talalay P. Regulatory mechanisms of monofunctional and bifunctional anticarcinogenic enzyme inducers in murine liver. Cancer Res 1988;48:4776-82.

[36] Buetler TM, Gallagher EP, Wang C, Stahl DL, Hayes JD, Eaton DL. Induction of Phase I and Phase II drug-metabolizing enzyme mRNA, protein, and activity by BHA, ethoxyquin, and oltipraz. Toxicol Appl Pharmacol 1995;135:45-57.

[37] Morel Y, Barouki R. Down-regulation of cytochrome P450 1A1 gene promoter by oxidative stress. J Biol Chem 1998;273:26969-76.

[38] Itoh K, Chiba T, Takahashi S, Ishii T, Igarashi K, Katoh Y, et al. An Nrf2/small Maf heterodimer mediates the induction of Phase II detoxifying enzyme genes through antioxidant response elements. Biochem Biophys Res Commun 1997;236:313-22.

[39] Chan K, Kan YW. Nrf2 is essential for protection against acute pulmonary injury in mice. Proc Natl Acad Sci USA 1999;96:12731-6.

[40] Thimmulappa RK, Mai KH, Srisuma S, Kensler TW, Yamamoto M, Biswal S. Identification of Nrf2-regulated genes induced by the chemopreventive agent sulforaphane by oligonucleotide microarrays. Cancer Res 2002,62:5196-203.

[41] Nguyen T, Sherratt PJ, Pickett CB. Regulatory mechanisms controlling gene expression mediated by the antioxidant response element. Ann Rev Pharmacol Toxicol 2003;43:233-60.

[42] Yeager RL, Reisman SA, Aleksunes LM, Klaassen CD. Introducing the 'TCDD-inducible AhR-Nrf2 gene battery'. Toxicol Sci 2009;111:238-46. 
[43] Münzel PA, Schmohl S, Heel H, Kälberer K, Bock-Hennig BS, Bock KW. Induction of human UDP glucuronosyltransferases (UGT1A6, UGT1A9, and UGT2B7) by t-butylhydroquinone and 2,3,7,8-tetrachlorodibenzo-p-dioxin in Caco-2 cells. Drug Metab Disp 1999;27:569-73.

[44] Mutoh S, Osabe M, Inoue K, Moore R, Pedersen L, Perera L, et al. Dephosphorylation of threonine 38 is required for nuclear translocation and activation of human xenobiotic receptor CAR (NR1/3). J Biol Chem 2009;284:34785-92.

[45] Arias IM, Gartner LM, Cohen M, Ezzer JB, Levi AJ. Chronic unconjugated hyperbilirubinemia with glucuronyltransferase deficiency. Am J Med 1969;47:395409.

[46] Sugatani J, Kojima H, Ueda A, Kakizaki S, Yoshinari K, Gong QH, et al. The phenobarbital response enhancer module in the human bilirubin UDPglucuronosyltransferase UGT1A1 gene and regulation by the nuclear receptor CAR. Hepatology 2001;33:1232-8.

[47] Sugatani J, Sueoshi T, Negishi M, Miva M. Regulation of the human UGT1A1 gene by nuclear receptors constitutive active/androstane receptor, pregnane $\mathrm{X}$ receptor and glucocorticoid receptor. Methods Enzymol 2005;400:92-104.

[48] Forman BM, Chen J, Evans RM. Hypolipidemic drugs, polyunsaturated fatty acids , and eicosanoids are ligands for peroxisome proliferator-activated receptors $\alpha$ and $\delta$. Proc Natl Acad Sci USA 1997;94:4312-7.

[49] Kliewer SA, Sundseth SS, Jones SA, Brown PJ, Wisely GB, Koble CS, et al. Fatty acids and eicosanoids regulate gene expression through direct interactions with peroxisome proliferator-activated receptors $\alpha$ and $\gamma$. Proc Natl Acad Sci USA 1997;94:4318-23.

[50] Lee SST, Pineau T, Drago J, Lee EJ, Owens JW, Kroetz DL, et al. Targeted disruption of the $\alpha$ isoform of the peroxisome proliferator-activated receptor gene in mice results in abolishment of the pleiotropic effects of peroxisome proliferators. Mol Cell Biol 1995;15:3012-22.

[51] Seneko-Effenberger K, Chen S, Brace-Sinnokrak E, Bonzo JA, Yueh MF, Argikar U, et al. Expression of the human UGT locus in transgenic mice by 4-chloro- 
6-(2,3-xylidino)-2-pyrimidylthioacetic acid (WY-14643) and implications on drug metabolism through peroxisome proliferator-activated receptor $\alpha$ activation. Drug Metab Disp 2007;35:419-27.

[52] Barbier O, Villeneuve L, Bocher V, Fontaine C, Pineda Torra I, Duhem C, et al. The UDP-glucuronosyltransferase $1 \mathrm{~A} 9$ enzyme is a peroxisome proliferator-activated receptor $\alpha$ and $y$ target gene. J Biol Chem 2003;278:13975-83.

[53] Barbier O, Duran-Sandoval D, Pineda-Torra I, Kosykh V, Fruchart JC, Staels B. Peroxisome proliferator-activated receptor $\alpha$ induces hepatic expression of the human bile acid glucuronidating UDP-glucuronosyltransferase 2B4 enzyme. J Biol Chem 2003;278:32852-60.

[54] Fernandez-Salguero P, Pineau T, Hilbert DM, McPhail T, Lee SST, Kimura S, et al. Immune system impairment and hepatic fibrosis in mice lacking the dioxinbinding Ah receptor. Science 1995;268:722-6.

[55] Soars MG, Petullo DM, Eckstein JA, Kasper SC, Wrighton SA. An assessment of UDP-glucuronosyltransferase induction using primary human hepatocytes. Drug Metab Disp 2004;32:140-8.

[56] Court MH. Interindividual variability in hepatic drug glucuronidation: studies into the role of age, sex, enzyme inducers, and genetic polymorphism using the human liver bank as a model system. Drug Metab Rev 2010;42:202-17.

[57] Izukawa T, Nakajima M, Fujiwara R, Yamanaka H, Fukami T, Takamiya M, et al. Quantitative analysis of UDP-glucuronosyltransferase (UGT) 1A and UGT2B expression levels in human livers. Drug Metab Disp 2009;37:1759-68.

[58] Chouinard S, Yueh MF, Tukey RH, Giton F, Fiet J, Pelletier G, et al. Inactivation by UDP-glucuronosyltransferase enzymes: The end of androgen signaling. J Steroid Biochem Mol Biol 2008;109:247-53.

[59] Köhle C, Bock KW. Activation of coupled Ah receptor and Nrf2 gene batteries by dietary phytochemicals in relation to chemoprevention. Biochem Pharmacol 2006,72:795-805. 
[60] Kalthoff S, Ehmer U, Freiberg N, Manns MP, Strassburg CP. Coffee induces expression of glucuronosyltransferases via the aryl hydrocarbon receptor and Nrf2 in liver and stomach. Gastroenterology 2010;139:1699-1710.

[61] Nakamura A, Nakajima M, Higashi E, Yamanaka H, Yokoi T. Genetic polymorphisms in the 5'-flanking region of human UDP-glucuronosyltransferase 2B7 affect the Nrf2-dependent transcriptional regulation. Pharmacogenet Genomics 2008;18:709-20.

[62] Sacerdoti D, Balazy M, Angeli P, Gatta A, McGiff JC. Eicosanoid excretion in hepatic cirrhosis. Predominance of 20-HETE. J Clin Invest 1997;100:1264-70.

[63] Puri P, Wiest MM, Cheung O, Mirshahi, F, Sargeant C, Min HK, et al. The plasma lipidomic signature of nonalcoholic steatohepatitis. Hepatology 2009;50:1827-38.

[64] Guillemette C, Levesque E, Harvey M, Bellemare J, Menard V. UGT genomic diversity: beyond gene duplication. Drug Metab Rev 2010;42:22-42.

[65] Finel M, Kurkela M. The UDP-glucuronosyltransferases as oligomeric enzymes. Current Drug Metab 2008;9:70-6.

[66] Mitra PS, Basu NK, Basu M, Chakraborty S, Saha T, Owens IS. Regulated phosphorylation of a major UDP-glucuronosyltransferase isoenzyme by tyrosine kinases dictates endogenous substrate selection for detoxification. J Biol Chem 2011;286:1639-48.

[67] Nebert DW, Dalton TP, Okey AB, Gonzalez FJ. Role of aryl hydrocarbon receptor-mediated induction of the CYP1 enzymes in environmental toxicity and cancer. J Biol Chem 2004;279:23847-50.

[68] Köhle C, Bock KW. Coordinate regulation of Phase I and II xenobiotic metabolisms by the Ah receptor and Nrf2. Biochem Pharmacol 2007;73:1853-62.

[69] Burchiel SW, Thompson TA, Lauer FT, Oprea TI. Activation of dioxin response element (DRE)-associated genes by benzo(a)pyrene 3,6-quinone and benzo(a)pyrene 1,6-quinone in MCF-10A human mammary epithelial cells. Toxicol Appl Pharmacol 2007;221:203-14. 
[70] Gschaidmeier H, Seidel A, Oesch F, Burchell B, Bock KW. Formation of monoand diglucuronides and of other glycosides of benzo(a)pyrene-3,6-quinol by V79 cellexpressed human phenol UDP-glucuronosyltransferases of the UGT1 gene complex. Biochem Pharmacol 1995;49:1601-6.

[71] Köhle C, Badary OA, Nill K, Bock-Hennig BS, Bock KW. Serotonin glucuronidation by Ah receptor- and oxidative stress-inducible human UDPglucuronosyltransferase (UGT) 1 A6 in Caco-2 cells. Biochem Pharmacol 2005;69:1397-1402.

[72] Jin Y, Penning TM. Aldo-keto reductases and bioactivation/detoxification. Ann Rev Pharmacol Toxicol 2007;47:263-92.

[73] Zheng Z, Park JY, Guillemette C, Schantz SP, Lazarus P. Tobacco carcinogen-detoxifying enzyme UGT1A7 and its association with orolarygeal cancer risk. J Natl Cancer Inst 2001;93:1411-8.

[74] Wishart GJ. Functional heterogeneity of UDP-glucuronosyltransferase as revealed by its differential development and inducibility by glucocorticoids. Biochem $\mathrm{J}$ 1978;174:485-9.

[75] Kapitulnik,J. Bilirubin: an endogenous product of heme degradation with both cytotoxic and cytoprotective properties. Mol Pharmacol 2004;66:773-9.

[76] Yueh MF, Tukey RH. Nrf2-Keap signaling pathway regulates UGT1A1 expression in vitro and in transgenic UGT1 mice. J Biol Chem 2007,282:8749-58.

[77] Caspersen CS, Reznik B, Weldy PL, Abildskov KM, Stark Ri, Garland M. Molecular cloning of the baboon UDP-glucuronosyltransferase $1 \mathrm{~A}$ gene family. Evolution of the primate UGT1 locus and relevance for models of human drug metabolism. Pharmacogenet Genom 2007;17:11-24.

[78] Huang W, Zhang J, Chua SS, Qatanani M, Han Y, Granata R, et al. Induction of bilirubin clearance by the constitutive androstane receptor (CAR). Proc Natl Acad Sci USA 2003;100:4156-61.

[79] Ritter JK, Kessler FK, Thompson MT, Grove AD, Auyeung DJ, Fisher RA. Expression and inducibility of the human bilirubin UDP-glucuronosyltransferase 
UGT1A1 in liver and cultured primary hepatocytes: evidence for both genetic and environmental influences. Hepatology 1999;30:476-84.

[80] Xie W, Yueh MF, Radominska-Pandya A, Saini SPS, Negishi Y, Bottroff BS, et al. Control of steroid, heme, and carcinogen metabolism by nuclear pregnane $\mathrm{X}$ receptor and constitutive androstane receptor. Proc Natl Acad Sci USA 2003;100:4150-5.

[81] Stocker R, Yamamoto Y, McDonagh AF, Glazer AN, Ames BN. Bilirubin is an antioxidant of possible physiological importance. Science 1987;235:1043-6.

[82] Sedlak TW, Saleh M, Higginson DS, Paul BD, Juluri KR, Snyder SH. Bilirubin and glutathione have complementary antioxidant and cytoprotective roles. Proc Natl Acad Sci USA 2009;106:5171-6.

[83] Lin JP, O'Donnell CJ, Schwaiger JP, Cupples LA, Lingenhel A, Hunt SC, et al. Association between the UGT1A $1 * 28$ allele, bilirubin levels, and coronary heart disease in the Framingham Heart Study. Circulation 2006;114:1476-81.

[84] Sugatani J, Nishitani S, Yamakawa K, Yoshinari K, Sueoshi T, Negishi M, et al. Transcriptional regulation of human UGT1A1 gene expression through distal and proximal promoter motifs: implication of defects in the UGT1A1 gene promoter. Naunyn-Schmiedeberg's Arch Pharmacol 2008;377:597-605.

[85] Li Y, Buckley D, Wang S, Klaassen CD, Zhong XB. Genetic polymorphisms in the TATA box and upstream phenobarbital-responsive enhancer module of the UGT1A1 promoter have combined effects on UDP-glucuronosyltransferase 1A1 transcription mediated by constitutive androstane receptor, pregnane $\mathrm{X}$ receptor, or glucocorticoid receptor in human liver. Drug Metab Disp 2009;37:1978-86.

[86] Fer M, Corcos L, Dreano Y, Plee-Gautier E, Salaün JP, Berthou F, et al. Cytochromes P450 from family 4 are the main omega hydroxylating enzymes in humans: CYP4F3B is the prominent player in PUFA metaboliosm. J Lipid Res 2008;49:2379-89.

[87] Turgeon D, Chouinard S, Belanger P, Picard S, Labbe JF, Borgeat P, et al. Glucuronidation of arachidonic and linoleic acid metabolites by human UDPglucuronosyltransferases. J Lipid Res 2003;44:1182-91. 
[88] Little JM, Kurkela M, Sonka J, Jäntti S, Ketola R, Bratton S, et al.

Glucuronidation of oxidized fatty acids and prostaglandin B1 and E2 by human hepatic and recombinant UDP-glucuronosyltransferases. J Lipid Res 2004;45:1694703.

[89] Kalthoff S, Ehmer U, Freiberg N, Manns MP, Strassburg CP. Interaction between oxidative stress sensor Nrf2 and xenobiotic-activated aryl hydrocarbon receptor in the regulation of the human phase II detoxifying UDPglucuronosyltransferase 1A10. J Biol Chem 2010,285:5993-6002.

[90] Miao W, Hu L, Scrivens J, Batist G. Transcriptional regulation of NF-E2 p45related factor (Nrf2) expression by the aryl hydrocarbon receptor-xenobiotic response element signaling pathway. J Biol Chem 2005;280:20340-8.

[91] Shin S, Wakabayashi N, Misra V, Biswal S, Lee GH, Agoston ES, et al. Nrf2 modulates aryl hydrocarbon receptor signaling: influence on adipogenesis. Mol Cell Biol 2007;27:7188-97.

[92] Ma Q, Kinneer K, Bi Y, Chan JY, Kan YW. Induction of murine $\mathrm{NAD}(\mathrm{P}) \mathrm{H}$ :quinone oxidoreductase by 2,3,7,8-tetrachloro-p-dioxin requires the CNC (cap'n'collar) basic leucine zipper transcription factor Nrf2 (nuclear factor erythroid 2related factor 2): cross-interaction between AhR (aryl hydrocarbon receptor) and Nrf2 signal transduction. Biochem J 2004;377:205-13.

[93] Patel RD, Hollingshead BD, Omiecinski CJ, Perdew GH. Aryl-hydrocarbon receptor activation regulates constitutive androstane receptor levels in murine and human liver. Hepatology 2007;46:209-18.

[94] Maglich JM, Stoltz CM, Goodwin B, Hawkins-Brown D, Moore JT, Kliewer SA. Nuclear pregnane $\mathrm{X}$ receptor and constitutive androstane receptor regulate overlapping but distinct sets of genes involved in xenobiotic detoxification. Mol Pharmacol 2002;62:638-46.

[95] Aouabdi S, Gibson G, Plant N. Transcriptional regulation of the PXR gene: Identification and characterization of a functional peroxisome proliferator-activated receptor $\alpha$ binding site within the proximal promoter of PXR. Drug Metab Disp 2006;34:138-44. 
[96] Sugatani J, Nishitani S, Yamakawa K, Yoshinari K, Sueoshi T, Negishi M, et

al. Transcriptional regulation of human UGT1A1 gene expression: activated glucocorticoid receptor enhances constitutive androstane receptor/pregnane $\mathrm{X}$ receptor-mediated UDP-glucuronosyltransferase $1 \mathrm{~A} 1$ regulation with glucocorticoid receptor-interacting protein 1. Mol Pharmacol 2004;67:845-55.

[97] Jia Y, Guo GL, Surapureddi S, Sarkar J, Qi C, Guo D, et al. Transcription coactivator peroxisome proliferator-activated receptor-binding protein/mediator 1 deficiency abrogates acetaminophen hepatotoxicity. Proc Natl Acad Sci USA 2005;102:12531-6.

[98] Masuyama $\mathrm{H}$, Nakatsukasa $\mathrm{H}$, Hiramatsu $\mathrm{Y}$. Effect of oncostatin $\mathrm{M}$ on uridine diphosphate-5'-glucuronosyltransferase $1 \mathrm{~A} 1$ through cross talk with constitutive androstane receptor. Mol Endocrinol 2010;24:745-53. 
Figure legends

Fig. 1. From differential induction to identification of ligand-activated transcription factors regulating human hepatic CYPs, UGTs and other xenobiotic-metabolizing enzymes (XMEs).

Fig. 2. Examples for possible feedback control between eicosanoid agonists of PPARa and their detoxification by hepatic UGTs. (a) CYP4F3B-generated vasocontrictory 20-HETE is a substrate of UGTs [88]. (b) 5-LOX-generated LTA4 is metabolized to inflammatory LTC4 (a metabolite of microsomal GSTs), and LTB4, a substrate of several UGTs [87]. (c) Several LOXs generate inflammatory HETEs which are substrates of indicated UGTs $[87,88]$. 
Table 1. Schematic representation of species differences of rat and human hepatic UGT regulation by ligand-activated transcription factors (LATFs). In contrast to the rat orthologous gene, human UGT1A7 is not expressed in liver but in the upper gastrointestinal tract. In addition to regulation by exogenous inducers, studies with LATF- and Nrf2-deficient mice suggest that basal expression of UGTs is also controlled by the discussed LATFs (indicated by +). Rat UGT induction data are taken from [17], human estimates are described in the text. + indicates $<2$-fold, ++ 2to 5 -fold, $+++>10$-fold induction in livers of rats or in human primary hepatocyte cultures. n.d., not determined;0, no induction detectable; (-), rat UGT1A4 and UGT1A9 are pseudogenes.

\begin{tabular}{|l|cccccc|}
\hline Ligand-activated transcription factors & \multicolumn{7}{|c|}{ UGT1A family members } \\
(LATFs) & 1 & 3 & 4 & 6 & 7 & 9 \\
\hline RAT: & \multicolumn{7}{|c}{ (induction factors) } \\
AhR & 0 & + & - & +++ & +++ & - \\
Nrf2 & 0 & + & - & + & + & - \\
PXR/CAR & ++ & 0 & - & + & + & - \\
PPARa & + & + & - & 0 & - & - \\
\hline HUMAN: & & & & & & \\
AhR & ++ & + & + & + & + & + \\
Nrf2 & + & + & + & + & + & + \\
PXR/CAR & ++ & + & + & + & n.d. & + \\
PPARa & + & + & + & + & n.d. & + \\
\hline
\end{tabular}


Table 2. Examples of multilevel crosstalk between UGT-controlling ligand-regulated transcription factors (LATFs). Details are discussed in the text.

\begin{tabular}{|l|l|}
\hline Modes of crosstalk & Affected UGTs \\
\hline (1) Genetic level & Multiple UGT1 members [33,68,89,90] \\
AhR-Nrf2 & UGT1A1 [93] \\
AhR-CAR & UGT1A1 [94] \\
PXR-AhR & \\
\hline $\begin{array}{l}\text { (2) Protein-protein interaction } \\
\text { AhR-Nrf2 }\end{array}$ & Multiple UGT1 members [68,89,92] \\
GR-, CAR-GRIP1 & UGT1A1 [96] \\
\hline $\begin{array}{l}\text { (3) Protein kinases/phosphatases } \\
\text { CAR-MAP kinases via oncostatin M }\end{array}$ & UGT1A1 [98] \\
\hline
\end{tabular}




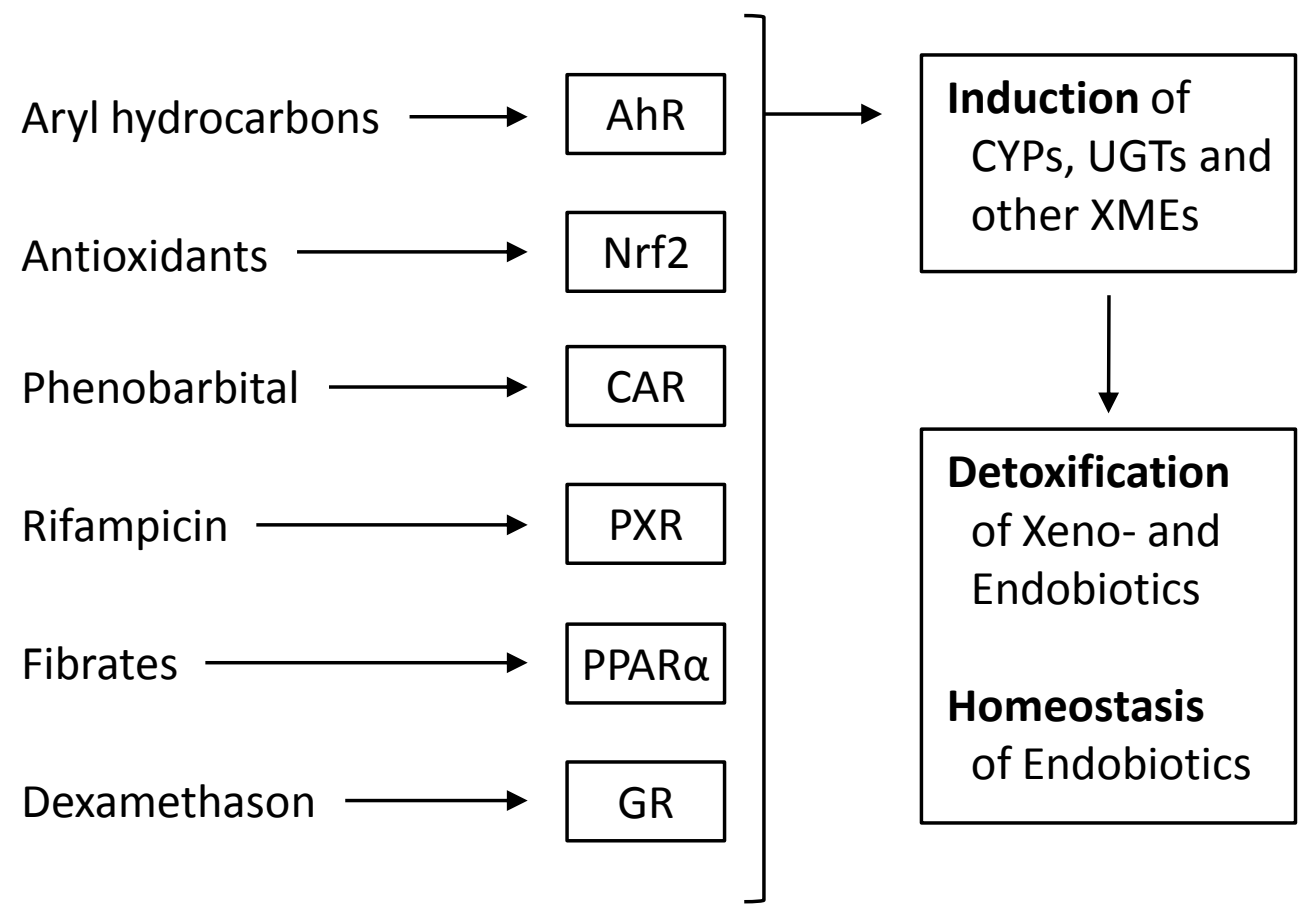


Arachidonic acid

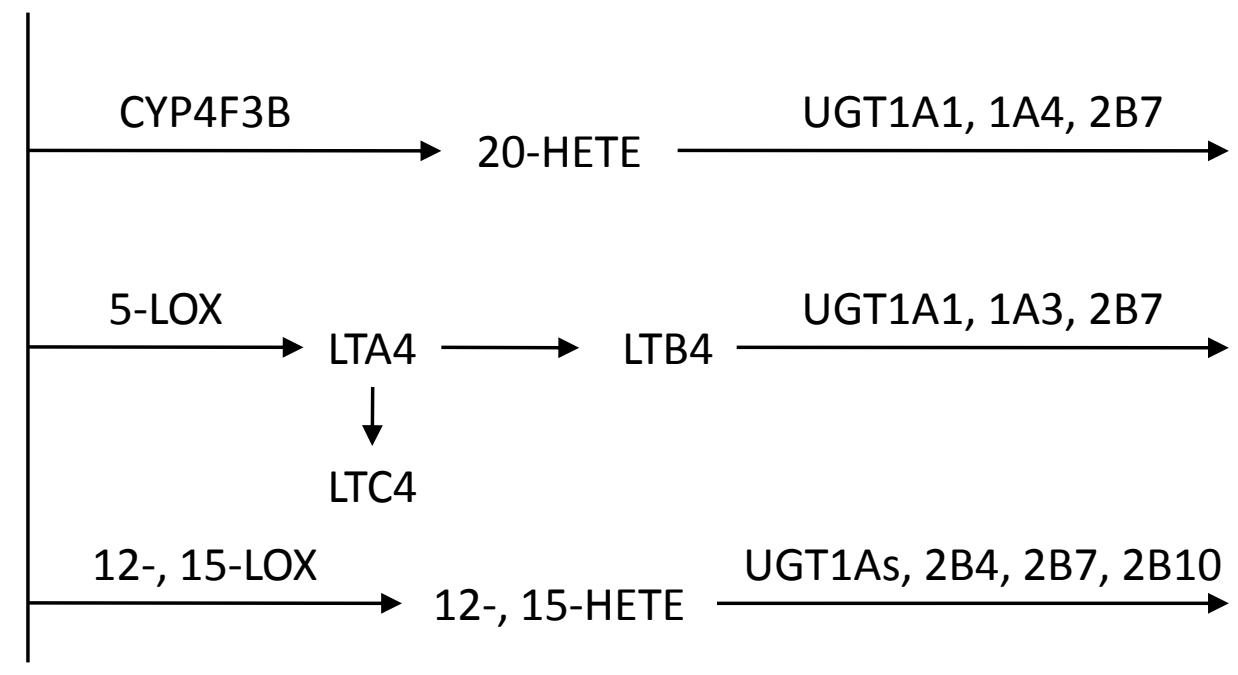




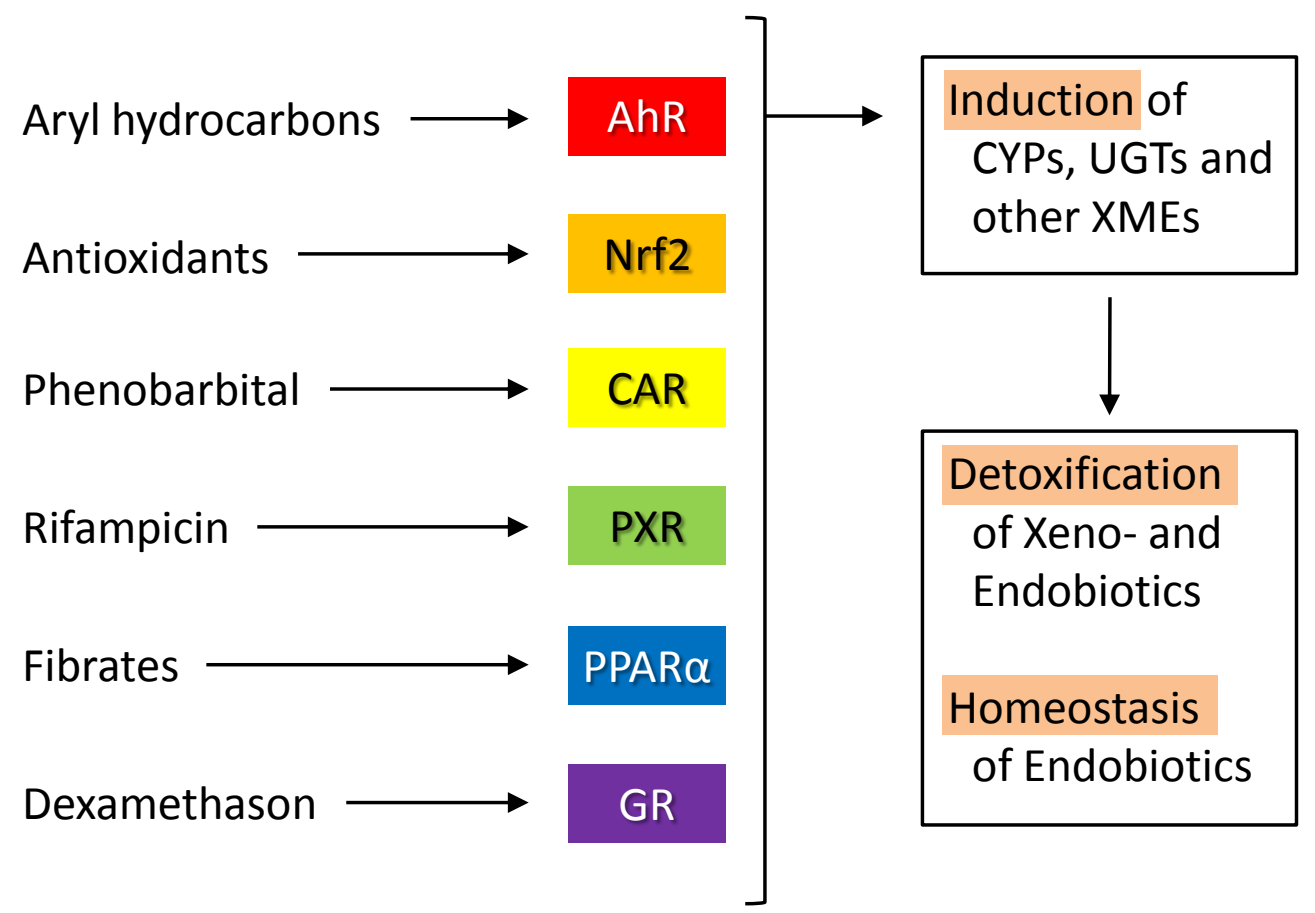

